\title{
High Voltage GaN Schottky Rectifiers
}

G.T. Dang ${ }^{(1)}$, A.P. Zhang ${ }^{(1)}$, F. Ren ${ }^{(1)}$, X.A. Cao ${ }^{(2)}$, S.J. Pearton ${ }^{(2)}$, H. Cho ${ }^{(2)}$, J. Han ${ }^{(3)}$, J.9. Chyi ${ }^{(4)}$, C.-M. Lee ${ }^{(4)}$, C.-C. Chuo ${ }^{(4)}$, S.N.G. Chu ${ }^{(5)}$ and R.G. Wilson ${ }^{(6)}$

\section{AND99-279}

(1)

Department of Chemical Engineering

University of Florida, Gainesville, FL 32611

(2) Department of Materials Science and Engineering

University of Florida, Gainesville, FL 32611

(3) Sandia National Laboratories

Albuquerque, NM 87185

(4) Department of Electrical Engineering

National Central University, Chung-Li 32054 Taiwan

(5) Bell Laboratories, Lucent Technologies

Murray Hill, NJ 07974

(6) Consultant, Stevenson Ranch, CA 91381

\section{Abstract}

Mesa and planar GaN Schottky diode rectifiers with reverse breakdown voltages $\left(V_{R B}\right)$ up to $550 \mathrm{~V}$ and $>2000 \mathrm{~V}$, respectively, have been fabricated. The on-state resistance, $R_{\mathrm{ON}}$, was $6 \mathrm{~m} \Omega \cdot \mathrm{cm}^{2}$ and $0.8 \Omega \mathrm{cm}^{2}$, respectively, producing figure-of-merit values for $\left(V_{R B}\right)^{2} / R_{O N}$ in the range $5-48 \mathrm{MW} \cdot \mathrm{cm}^{-2}$. At low biases the reverse leakage current was proportional to the size of the rectifying contact perimeter, while at high biases the current was proportional to the area of this contact. These results suggest that at low reverse biases, the leakage is dominated by the surface component, while at higher biases the bulk component dominates. On-state voltages were $3.5 \mathrm{~V}$ for the $550 \mathrm{~V}$ diodes and $\geq 15$ for the $2 \mathrm{kV}$ diodes. Reverse recovery times were $<0.2 \mu \mathrm{sec}$ for devices switched from a forward current density of $\sim 500 \mathrm{~A} \cdot \mathrm{cm}^{-2}$ to a reverse bias of $100 \mathrm{~V}$. 


\section{DISCLAIMER}

This report was prepared as an account of work sponsored by an agency of the United States Government. Neither the United States Government nor any agency thereof, nor any of their employees, make any warranty, express or implied, or assumes any legal liability or responsibility for the accuracy, completeness, or usefulness of any information, apparatus, product, or process disclosed, or represents that its use would not infringe privately owned rights. Reference herein to any specific commercial product, process, or service by trade name, trademark, manufacturer, or otherwise does not necessarily constitute or imply its endorsement, recommendation, or favoring by the United States Government or any agency thereof. The views and opinions of authors expressed herein do not necessarily state or reflect those of the United States Government or any agency thereof. 


\section{DISCLAIMER}

Portions of this document may be illegible in electronic image products. Images are produced from the best available original document. 


\section{Introduction}

Wide bandgap diode rectifiers are attractive devices for a range of high power, high temperature applications, including solid-state drives for heavy motors, pulsed power for electric vehicles or ships, drive trains for electric automobiles and utilities transmission and distribution. ${ }^{(1)}$ To date, most effort has been focussed on $\mathrm{SiC}$ and a full range of power devices including thyristors, insulated gate bipolar transistors, metal oxide semiconductor field effect transistors and pin and Schottky rectifiers, has been reported. ${ }^{(2-13)}$ The GaN materials systems is also attractive for ultra high power electronic devices because of its wide bandgap and excellent transport properties. ${ }^{(13,14)}$ A potential disadvantage for thick, carrier-modulated devices is the low minority carrier lifetime, but for unipolar devices $\mathrm{GaN}$ has the potential for higher switching speed and larger standoff voltage than SiC. Efforts to fabricate high power GaN devices are in their infancy and there have been reports of simple Schottky rectifiers with reverse breakdown voltage $\left(V_{R B}\right)$ in the range $350-450 \mathrm{~V}^{(15,16)}$ While pin rectifiers would be expected to have larger blocking voltages, the Schottky rectifiers are attractive for their faster switching speed and lower forward voltage drop.

In this paper we report on the fabrication of mesa and planar GaN Schottky diode rectifiers. We have found that mesa structures formed by dry etching can have similar $V_{R B}$ values to planar diodes provided the dry etch damage is removed by annealing or wet etch cleanup. The mesa diodes have lower specific on-resistances because ohmic contacts can be formed on a heavily doped GaN layer below the undoped standoff layer. 


\section{Experimental}

Two different types of GaN were grown on c-plane sapphire substrates by Metal Organic Chemical Vapor Deposition using trimethylgallium and ammonia as the precursors. For structures intended for vertical depletion, a $1 \mu \mathrm{m}$ thick $\mathrm{n}^{+}\left(3 \times 10^{18} \mathrm{~cm}^{-3}\right.$, Si doped) contact layer was grown in a low temperature GaN buffer and then followed with either 4 or $11 \mu \mathrm{m}$ of undoped $\left(\mathrm{n} \sim 2 \times 10^{16} \mathrm{~cm}^{-3}\right) \mathrm{GaN}$. For structures intended for lateral depletion, a $3 \mu \mathrm{m}$ thick resistive $\left(\mathrm{n}<10^{15}\right.$ $\mathrm{cm}^{-3}$ ) active region was grown on a low temperature buffer.

The mesas were formed by $\mathrm{Cl}_{2} / \mathrm{Ar}$ Inductively Coupled Plasma etching ( $300 \mathrm{~W}$ source power, $40 \mathrm{~W}$ rf chuck power, corresponding to a dc self-bias of $-85 \mathrm{~V}$ ) at a rate of $1100 \AA \cdot \mathrm{min}^{-1}$,

using a photoresist mask. The samples were annealed at $\sim 800^{\circ} \mathrm{C}$ to remove dry etch damage. ${ }^{(17)}$ Ohmic contacts were formed by lift-off of e-beam evaporated $\mathrm{Ti} / \mathrm{Al}$, subsequently annealed at $750^{\circ} \mathrm{C}$ for 20 secs under $\mathrm{N}_{2}$. The rectifying contacts with diameter $60-1100 \mu \mathrm{m}$ were formed by lift-off of e-beam evaporated Pt/Au.

On the lateral diodes, $\mathrm{n}^{+}$contact regions were formed by implantation of $\mathrm{Si}^{+}$followed by annealing at $1150^{\circ} \mathrm{C}$ for $10 \operatorname{secs}$ under $\mathrm{N}_{2}$. The $\mathrm{GaN}$ was protected by a dielectric encapsulant during the annealing step. The ohmic and rectifying contacts were formed as described above. Schematics of the two different structures are shown in Figure 1. The current-voltage (I-V) characteristics were recorded on a HP 4145A parameter analyzer.

\section{Results and Discussion}

\section{(a) Mesa Diodes}

A typical I-V characteristic for the $11 \mu \mathrm{m}$ undoped depletion layer diodes is shown in 
Figure 2. The $\mathrm{V}_{\mathrm{RB}}$ for these devices was $550 \mathrm{~V}$ at $25^{\circ} \mathrm{C}$, with typical $\mathrm{V}_{\mathrm{F}}$ 's of $3-5 \mathrm{~V}\left(100 \AA \mathrm{cm}^{-2}\right)$. The specific on-resistance was in the range $6-10 \mathrm{~m} \Omega \cdot \mathrm{cm}^{2}$, leading to a figure-of-merit $\left(\mathrm{V}_{\mathrm{RB}}\right)^{2} / \mathrm{R}_{\mathrm{ON}}$ of $48 \mathrm{MW} \cdot \mathrm{cm}^{-2}$. The breakdown voltage is approximately a factor of 3 lower than the theoretical maximum value for this doping and thickness. Secondary Ion Mass Spectrometry showed that the main background impurities present were $\mathrm{O}\left(\sim 9 \times 10^{17} \mathrm{~cm}^{-3}\right), \mathrm{C}\left(\sim 10^{17} \mathrm{~cm}^{-3}\right), \mathrm{Si}$ $\left(4 \times 10^{17} \mathrm{~cm}^{-3}\right)$ and $\mathrm{H}\left(3 \times 10^{18} \mathrm{~cm}^{-3}\right)$. While $\mathrm{O}$ and Si can produce shallow donor states, it is clear that these impurities have only fractional electrical activation. The surfaces of the material were relatively smooth with root-mean-square roughness of $\sim 0.2 \mathrm{~nm}\left(1 \mathrm{x} 1 \mu \mathrm{m}^{2}\right)$ and $1.5 \mathrm{~nm}\left(10 \times 10 \mathrm{~m}^{2}\right)$. Cross-sectional transmission electron microscopy (TEM) views of the structure are shown in Figure 3. The threading dislocation density at the top surface was $\sim 10^{8}-\mathrm{cm}^{-2}$, typical of high quality, heteroepitaxial GaN.

For the $4 \mu \mathrm{m}$ thick active region structure, the room temperature $V_{R B}$ was $356 \mathrm{~V}$, with typical $V_{F}$ 's of 3-5V $\left(100 \AA \cdot \mathrm{cm}^{-2}\right)$. The specific on-resistance of these devices was $28 \mathrm{~m} \Omega \cdot \mathrm{cm}^{2}$, leading to a value of $\left(V_{R B}\right)^{2} / R_{O N}$ of $42 \mathrm{MW} \cdot \mathrm{cm}^{-2}$. Once again the breakdown voltage was approximately a factor of 3 lower than the theoretical maximum value. In these diodes we observed a negative temperature coefficient for $V_{R B}$, with a value of $-0.92 \mathrm{~V} \cdot \mathrm{K}^{-1}$ in the range 25$50^{\circ} \mathrm{C}$ and $0.17 \mathrm{VK}^{-1}$ in the range $50-150^{\circ} \mathrm{C}$. If impact ionization were the cause of breakdown, one would expect to observe a positive temperature coefficient for $\mathrm{V}_{\mathrm{RB}}$, as has been reported for GaN heterostructure field effect transistors and $\mathrm{p}^{+} \mathrm{pn}^{+}$diodes. ${ }^{(18,20)}$ In analogy with some reports from some SiC Schottky diodes with negative $V_{R B}$ temperature coefficients, we believe the breakdown mechanism in our diodes is defect-assisted tunnelling through surface or bulk states. $^{(10)}$ 
Figure 4 shows the reverse current density in the $4 \mu \mathrm{m}$ active layer diodes at a low bias $(15 \mathrm{~V})$ and a bias approximately half of $\mathrm{V}_{\mathrm{RB}}$ (i.e. $150 \mathrm{~V}$ ). For the low bias condition the current density scales as the perimeter/area ratio, while at the high bias condition the current density is constant with this ratio. This data indicates that at low biases the surface perimeter currents are the dominant contribution, while at higher biases the current is proportional to contact area indicating that bulk leakage is dominant. In $\mathrm{SiC}$ devices it has been reported that increases in leakage current in the voltage range approximately half the $V_{R B}$ of the diodes are due to the presence of this interfacial layer (typically as oxide) between the rectifying contact and the

semiconductor. This oxide can sustain a voltage drop, but is thin enough for carrier tunnelling. ${ }^{(6)}$ Figure 5 shows reverse recovery current transient waveforms from a diode switched from a forward current density of $500 \mathrm{~A} \cdot \mathrm{cm}^{-2}$ to a reverse voltage of $100 \mathrm{~V}$. The recovery time is $<0.2 \mu \mathrm{sec}$, similar to values reported for $\mathrm{SiC}$ rectifiers. ${ }^{(6)}$

In all wide bandgap diode rectifiers (both $\mathrm{SiC}$ and the $\mathrm{GaN}$ reported here), the magnitude of the reverse leakage currents are generally $1-2$ orders higher than the theoretical values based on image-force lowering of the Schottky barrier. ${ }^{(6)}$ Our GaN diodes have slightly higher reverse leakage relative to $\mathrm{SiC}$ devices at the same biases, which probably reflects the earlier stage of maturity of the former.

\section{(b) Lateral, Planar Diodes}

Figure 6 shows a room temperature I-V characteristic from the $3 \mu \mathrm{m}$ thick structure. The $V_{R B}$ was $>2000 \mathrm{~V}$ (the limit of our test setup), with a best $V_{F}$ of $15 \mathrm{~V}$ (more typically $50-60 \mathrm{~V}$ ). The specific on-resistance was $0.8 \Omega \mathrm{cm}^{2}$ producing a $\left(\mathrm{V}_{\mathrm{RB}}\right)^{2} / \mathrm{R}_{\mathrm{ON}}$ value of $>15 \mathrm{MW} \cdot \mathrm{cm}^{-2}$. For this structure we believe the depletion is lateral, because for the larger thickness and doping a 
vertical device would breakdown at $\sim 1000 \mathrm{~V}$. TEM cross-sections of the structure showed a threading dislocation density of $-3 \times 10^{8} \mathrm{~cm}^{-2}$, typical of high quality GaN of this thickness.

To place the results in context, Figure 7 shows a plot of specific on-resistance for Schottky diode rectifiers as a function of breakdown voltage. The lines are theoretical values for $\mathrm{Si}, 4 \mathrm{H}-\mathrm{SiC}, 6 \mathrm{H}-\mathrm{SiC}$ and $\mathrm{GaN}$ and the points are experimental values for $\mathrm{SiC}$ and $\mathrm{GaN}$ devices. ${ }^{(2-}$ $6,10,13,15,16)$ Note that the $356 \mathrm{~V}$ and $2 \mathrm{kV}$ diodes reported here essentially fit on the line expected for perfect Si devices, but the $550 \mathrm{~V}$ diode has clearly superior performance to $\mathrm{Si}$. However there is still significant improvement required before $\mathrm{GaN}$ matches the reported performance of $\mathrm{SiC}$ Schottky rectifiers.

\section{Summary and Conclusions}

The main conclusions of our study can be summarized as follows:

(i) Mesa.diodes with $V_{R B}$ equal to planar diodes, but with improved $R_{O N}$ values, have been fabricated in $\mathrm{GaN}$ using $\mathrm{Cl}_{2} / \mathrm{Ar}$ dry etching, followed by annealing to remove the plasma damage.

(ii) $\mathrm{V}_{\mathrm{RB}}$ values up to $550 \mathrm{~V}$ with figure-of-merit $48 \mathrm{MW} \cdot \mathrm{cm}^{-2}$ have been achieved on mesa diodes fabricated on thick ( $12 \mu \mathrm{m}$ total) MOCVD GaN.

(iii) $\mathrm{V}_{\mathrm{RB}}$ values $>2 \mathrm{kV}$ have been achieved in lateral diodes fabricated on resistive GaN grown by MOVCD.

(iv) For the mesa diodes, the $\mathrm{V}_{\mathrm{RB}}$ values are approximately a factor of three lower than the theoretical maximum for $\mathrm{GaN}$ based on avalanche breakdown. Similarly, the reverse leakage currents are several orders of magnitude higher than the theoretical values. 
(v) At low reverse biases, the leakage current is dominated by contributions from the surface, while at higher biases bulk leakage dominates.

\section{Acknowledgments}

The work at UF is partially supported by a DARPA/EPRI grant (D. Radack/J. Melcher), no. MDA 972-98-1-006 monitored by ONR (J.C. Zolper). The work at NCU is sponsored by the

National Science Council of R.O.C. under contract no. NSC-88-2215-E-008-012. The work of

RGW is partially supported by a grant from ARO (J.M. Zavada).

Sandia is a multiprogram laboratory operated by Sandia Corporation, a

Lockheed Martin Company, for the

United States Department of Energy

under contract DE-AC04-94AL85000. 


\section{References}

1. E.R. Brown, "Megawatt Electronics," Solid-State Electronics 42, 2117 (1998).

2. Q. Wahab, T. Kimoto, A. Ellison, C. Hallin, M. Tuominen, R. Yakimova, A. Henry, J.P. Bergman and E. Janzen, "A 3kV Schottky Barrier Diode in 4H-SiC," Appl. Phys. Lett. $\underline{72}, 445$ (1998).

3. K.J. Schoen, J.M. Woodall, J.A. Cooper and M.R. Melloch, "Design Considerations and Experimental Analysis of High Voltage SiC Schottky Barrier Rectifiers," IEEE Trans. Electron. Dev. $\underline{45}, 1595$ (1998).

4. O. Kordina, J.P. Bergman, A. Henry, E. Janzen, S. Savage, J. Andre, L.P. Ramberg, U. Lindefelt, W. Hermansson and K. Bergman, "A 4-5kV SiC Rectifier," Appl. Phys. Lett. 67, $1561(1995)$.

5. R. Raghunthan, D. Alok and B.J. Baliga, "High Voltage 4H-SiC Schottky Barrier Diodes," IEEE Electron. Dev. Lett. 16, 226 (1995).

6. V. Khemka, R. Patel, T.P. Chow and R.J. Gutmann, "Design Considerations and Experimental Analysis for SiC Power Rectifiers," Solid-State Electronics 4ㄹ, 1998 (1999).

7. M. Trivdei and K. Shenai, "Performance Evaluation of High Power, Wide Bandgap Semiconductor Rectifiers," J. Appl. Phys. $\underline{85}, 6889$ (1999).

8: $\quad$ G. Kelner and M. Shur, "SiC Electronics," in Properties of SiC, ed. G.L. Harris, EMIS Data Review 13 (INSPEC, IEE, London, 1995).

9. B.J. Baliga, Power Semiconductor Devices (ITP Publishers, Boston, 1996).

10. C.I. Harris and A.O. Konstantinov, "Recent Developments in SiC Device Research," Physica Scripta T고, 27 (1999). 
11. J.N. Shenoy, M.R. Melloch and J.A. Cooper, Jr., "High Voltage, Double Implanted Power MOSFETs in 6H-SiC," IEEE Electron. Dev. Lett. 18, 93 (1997).

12. J.B. Casady, A.K. Agarwal, S. Seshadri, R.R. Siergiej, L.B. Rowland, M. MacMillan, D.C. Sheridan, P.A. Sanger and C.D. Brandt, "4-H SiC Power Devices for Use in Power Electronic Motor Control," Solid-State Electron. $\underline{42}, 2165$ (1998).

13. C.E. Weitzel, J.W. Palmour, C.H. Carter, Jr., K.J. Moore, K.J. Nordquist, S. Allen, C. Thero and M. Bhatnagar, "SiC High Power Devices," IEEE Trans. Electron. Dev. $\underline{43}$, 1732 (1996).

14. M. Shur, "GaN-based Transistors for High Power Applications," Solid-State Electron. $\underline{42}, 2131$ (1998).

15. Z.Z. Bandic, P.M. Bridger, E.C. Piquette, T.C. McGill, R.P. Vaudo, V.M. Phanse and J.M. Redwing, "High Voltage (450V) GaN Schottky Rectifiers," Appl. Phys. Lett. 74, 1266 (1999).

16. J.-I. Chyi, C.-M. Lee, C.-C. Chuo, G.C. Chi, G.T. Dang, A.P. Zhang, F. Ren, X.A. Cao, S.J. Pearton, S.N.G. Chu and R.G. Wilson, "Growth and Device Performance of GaN Schottky Rectifiers," MRS Internet J. Nitride Semi. Res. 4 , 8 (1999).

17. X.A. Cao, H. Cho, S.J. Pearton, G.T. Dang, A.P. Zhang, F. Ren, R.J. Shul, L. Zhang, R. Hickman and J.M. Van Hove, "Depth and Thermal Stability of Dry Etch Damage in : GaN," Appl. Phys. Lett. 75, 232 (1999).

18. N. Dyakonova, A. Dickens, M.S. Shur, R. Gaska and J.W. Yang, "Temperature Dependence of Impact Ionization in AlGaN-GaN HEMTs," Appl. Phys. Lett. $\underline{72}, 2562$ (1998). 
19. V.A. Dmitriev, K.G. Irvine, C.H. Carter, Jr., N.I. Kuznetsov and E.V. Kalinic, "Electric Breakdown in GaN p-n Junctions," Appl. Phys. Lett. $\underline{68}, 229$ (1996).

20. A. Osinsky, M.S. Shur and R. Gaska, "Temperature Dependence of Breakdown Field in p-i-n GaN Diodes," Mat. Res. Soc. Symp. Proc. 1ㅡ, 15 (1998). 


\section{Figure Captions}

Figure 1. Schematic of mesa and planar GaN diodes.

Figure 2. I-V characteristic at $25^{\circ} \mathrm{C}$ from mesa diode with $11 \mu \mathrm{m}$ thick blocking layer.

Figure 3. TEM cross-sections of the MOCVD-grown structure with $11 \mu \mathrm{m}$ thick blocking layer.

Figure 4. Reverse current density in $\mathrm{GaN}$ mesa diodes ( $4 \mu \mathrm{m}$ thick blocking layer) as a function of perimeter-to-area ratio, at two different reverse biases.

Figure 5. Reverse recovery current transient waveform measured for $\mathrm{GaN}$ rectifier $(550 \mu \mathrm{m}$ diameter) at $25^{\circ} \mathrm{C}$. The device was switched from a forward current density of $500 \mathrm{~A} \cdot \mathrm{cm}^{-2}$ to a reverse voltage of $100 \mathrm{~V}$.

Figure 6. I-V characteristic at $25^{\circ} \mathrm{C}$ from planar diode with $3 \mu \mathrm{m}$ thick blocking layer.

Figure 7. Specific on-resistance versus blocking voltage for $\mathrm{SiC}$ and $\mathrm{GaN}$ Schottky diode rectifiers. The performance limits of $\mathrm{Si}, \mathrm{SiC}$ and $\mathrm{GaN}$ devices are shown by the solid lines. 

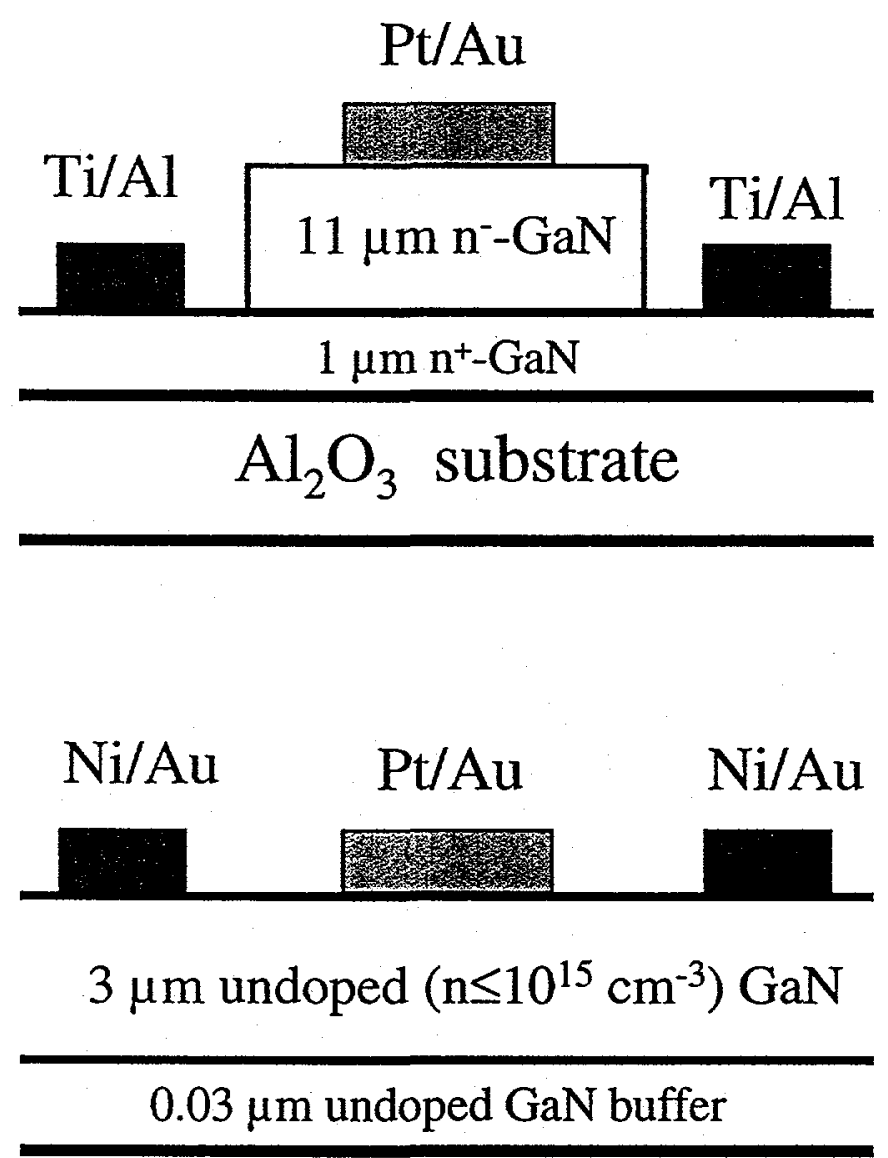

$\mathrm{Al}_{2} \mathrm{O}_{3}$ substrate 

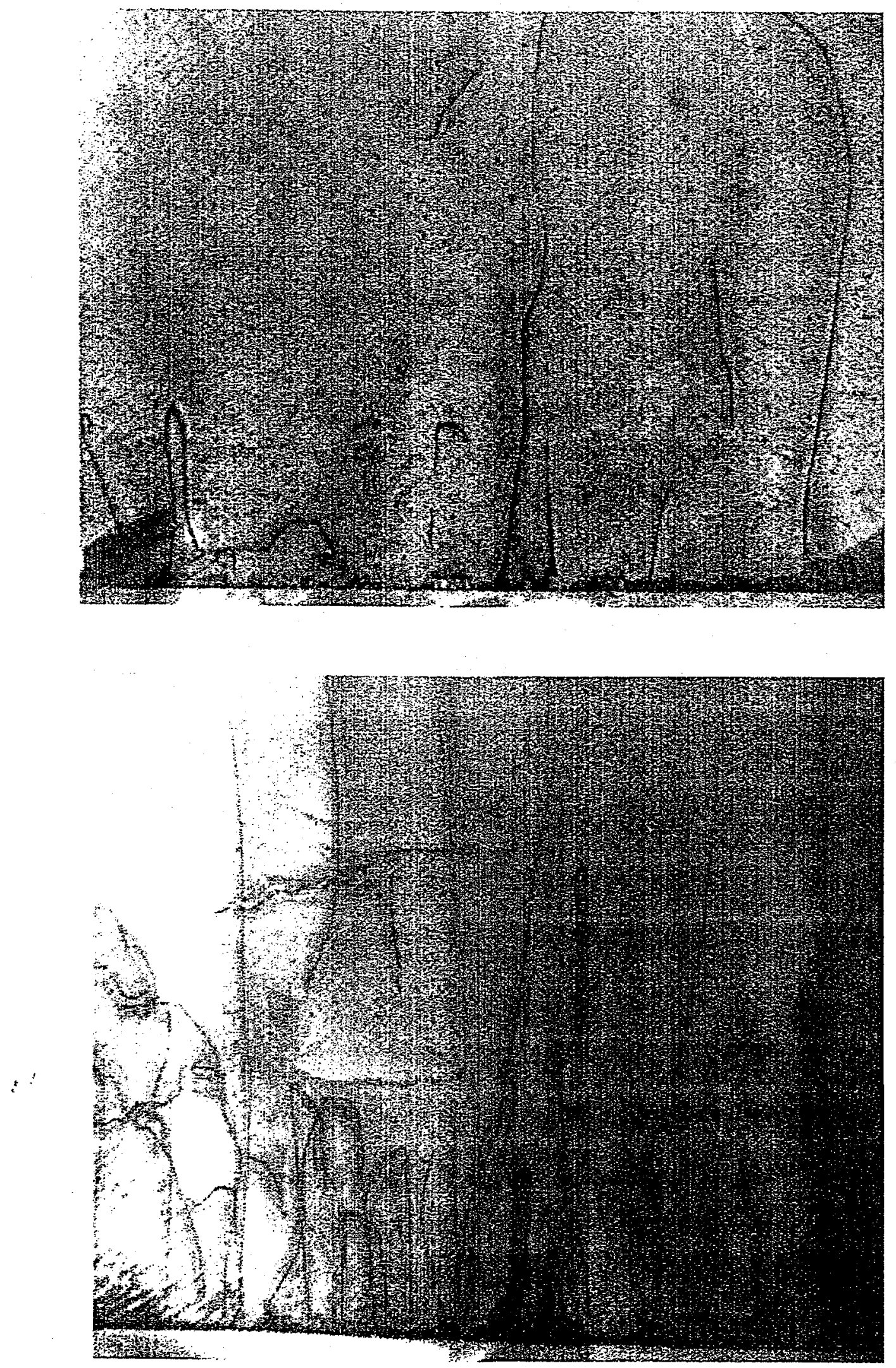


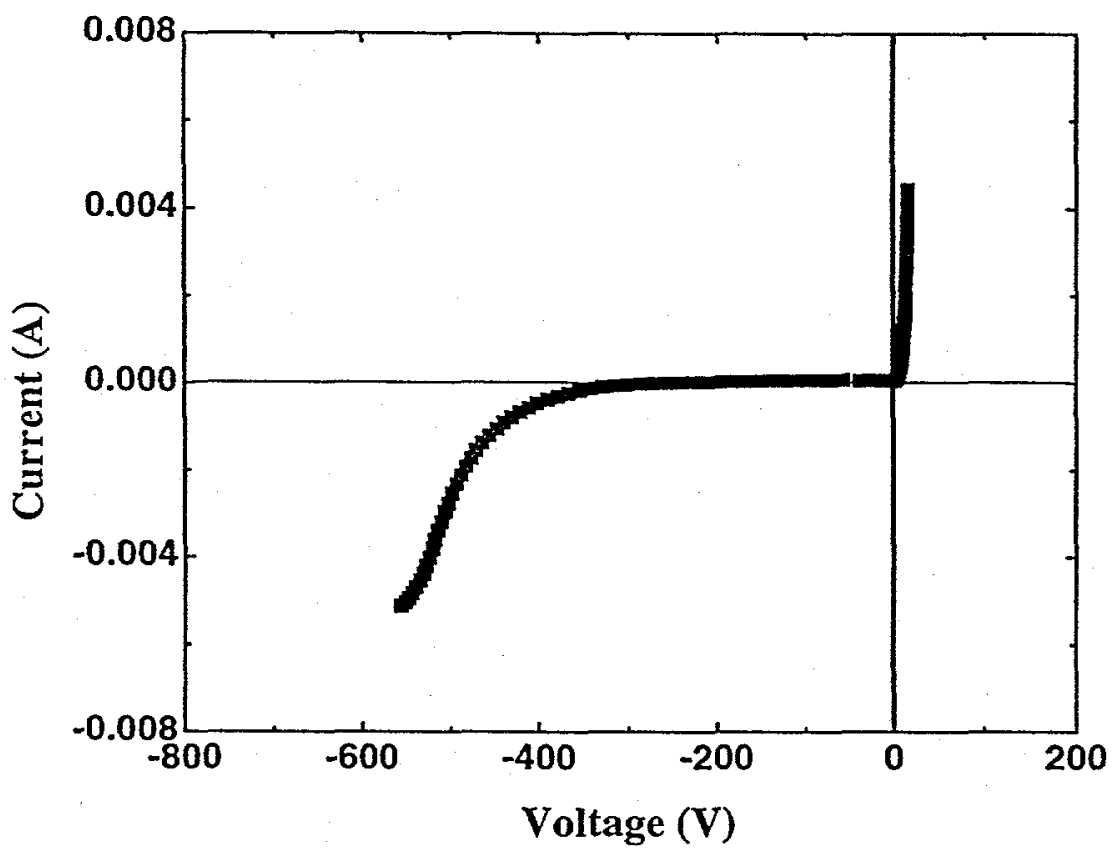




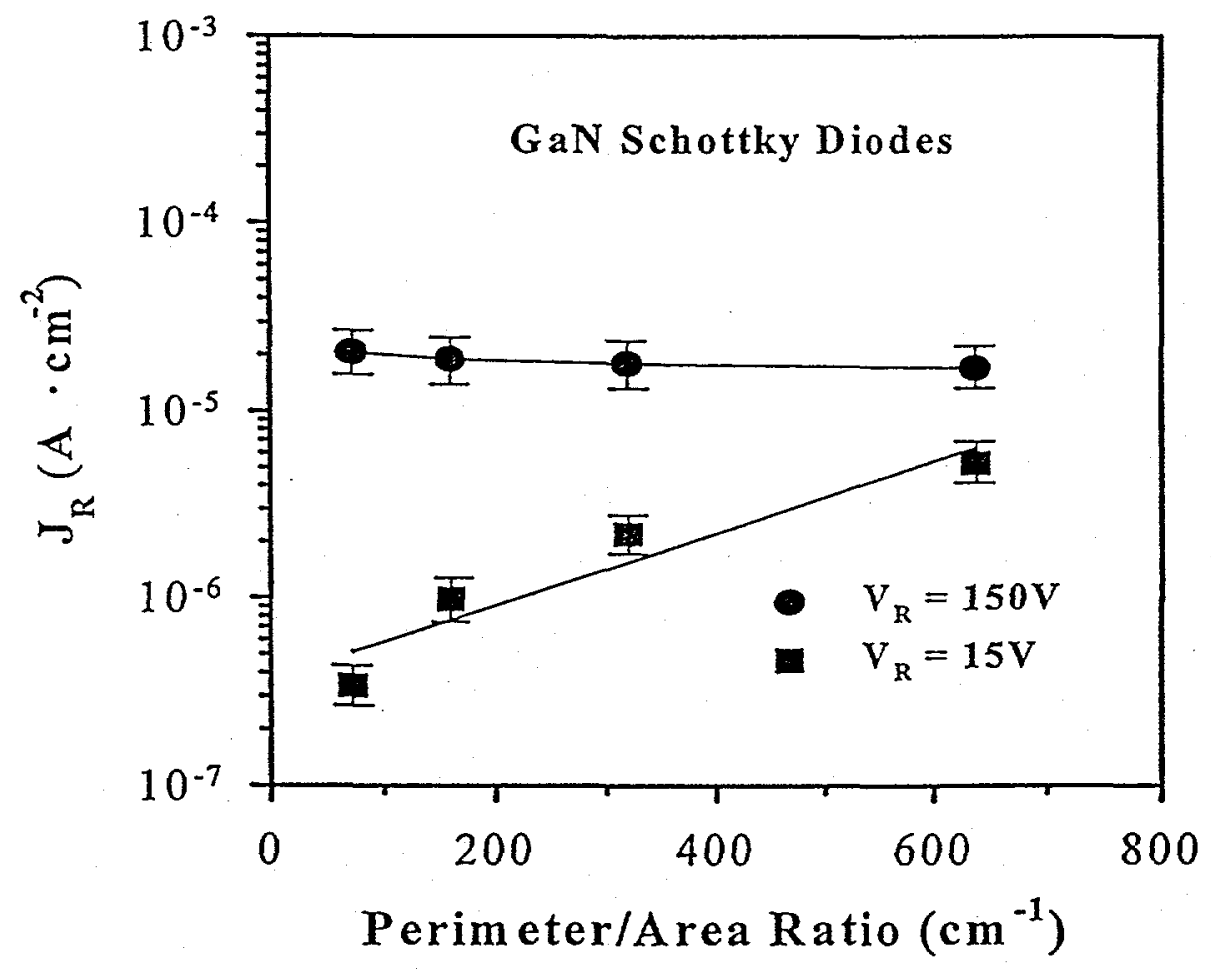




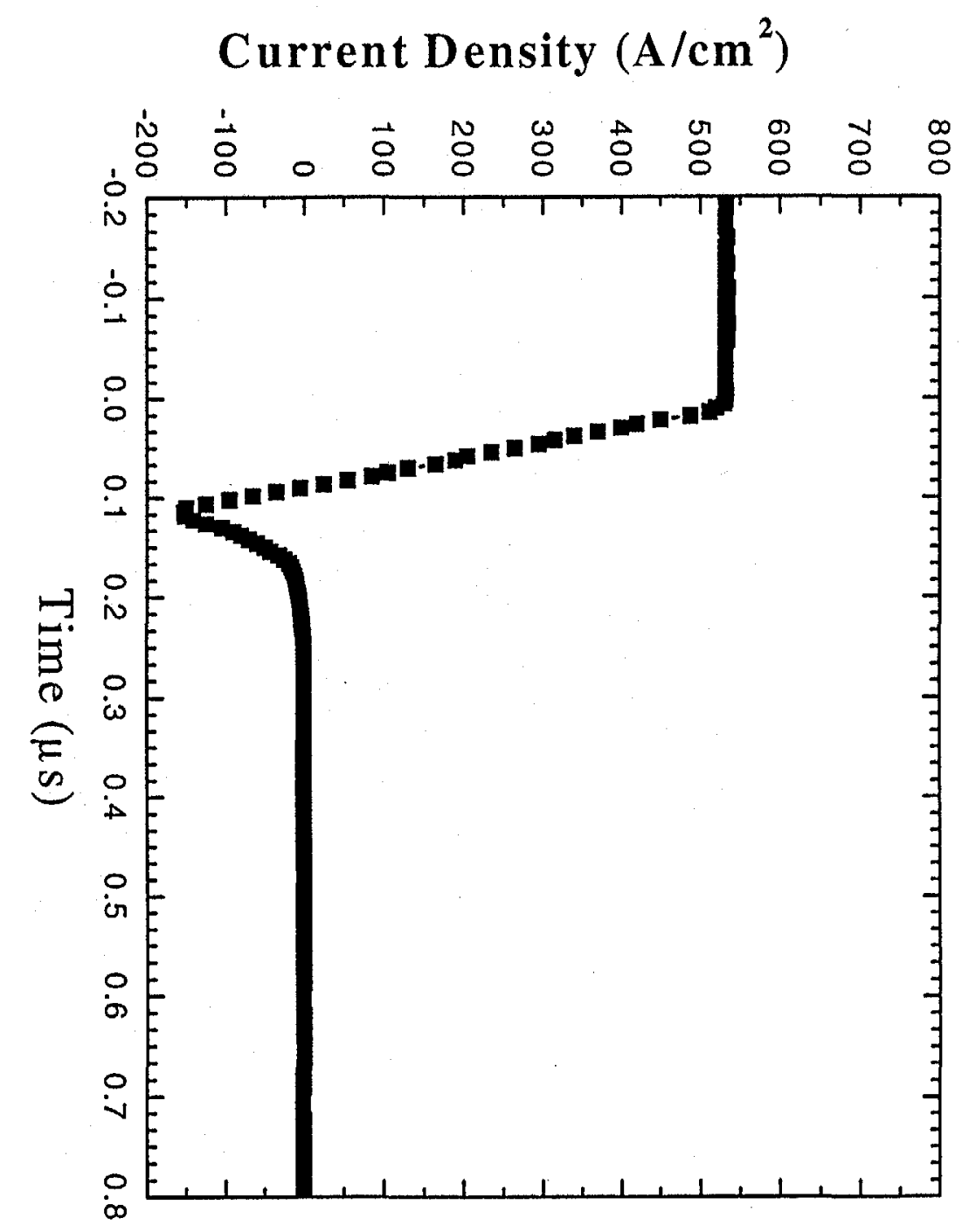




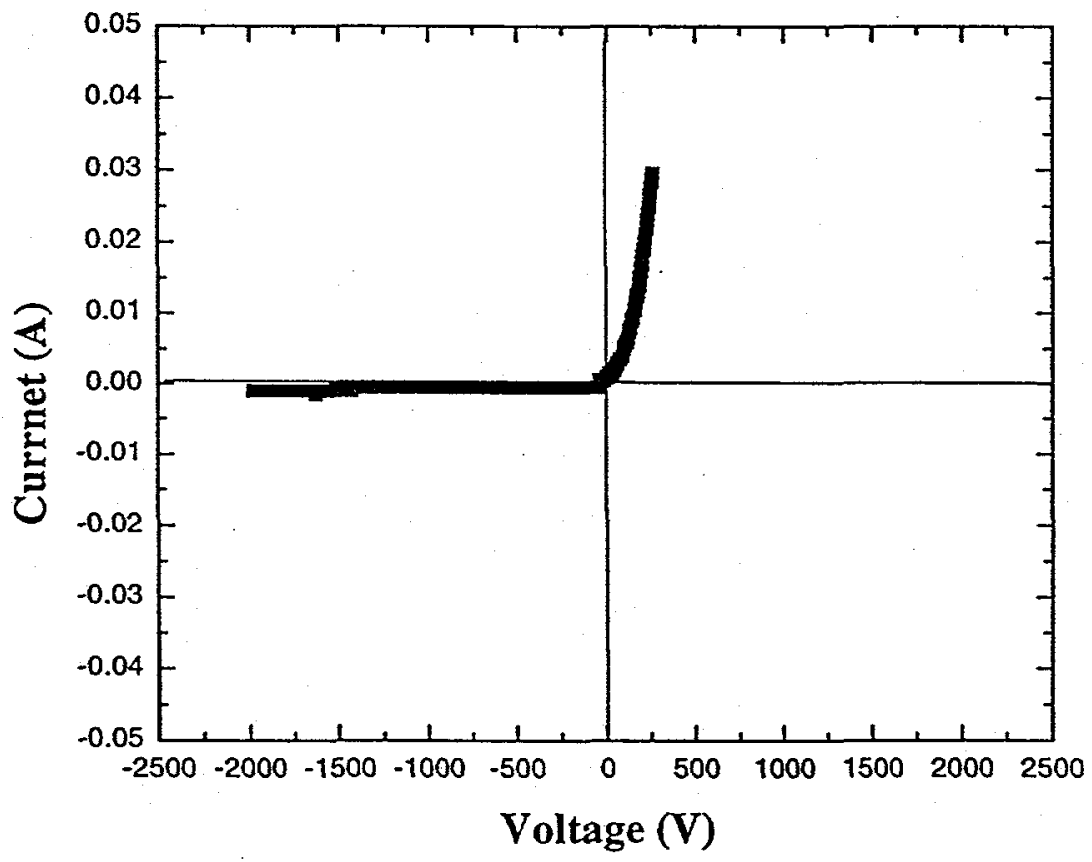




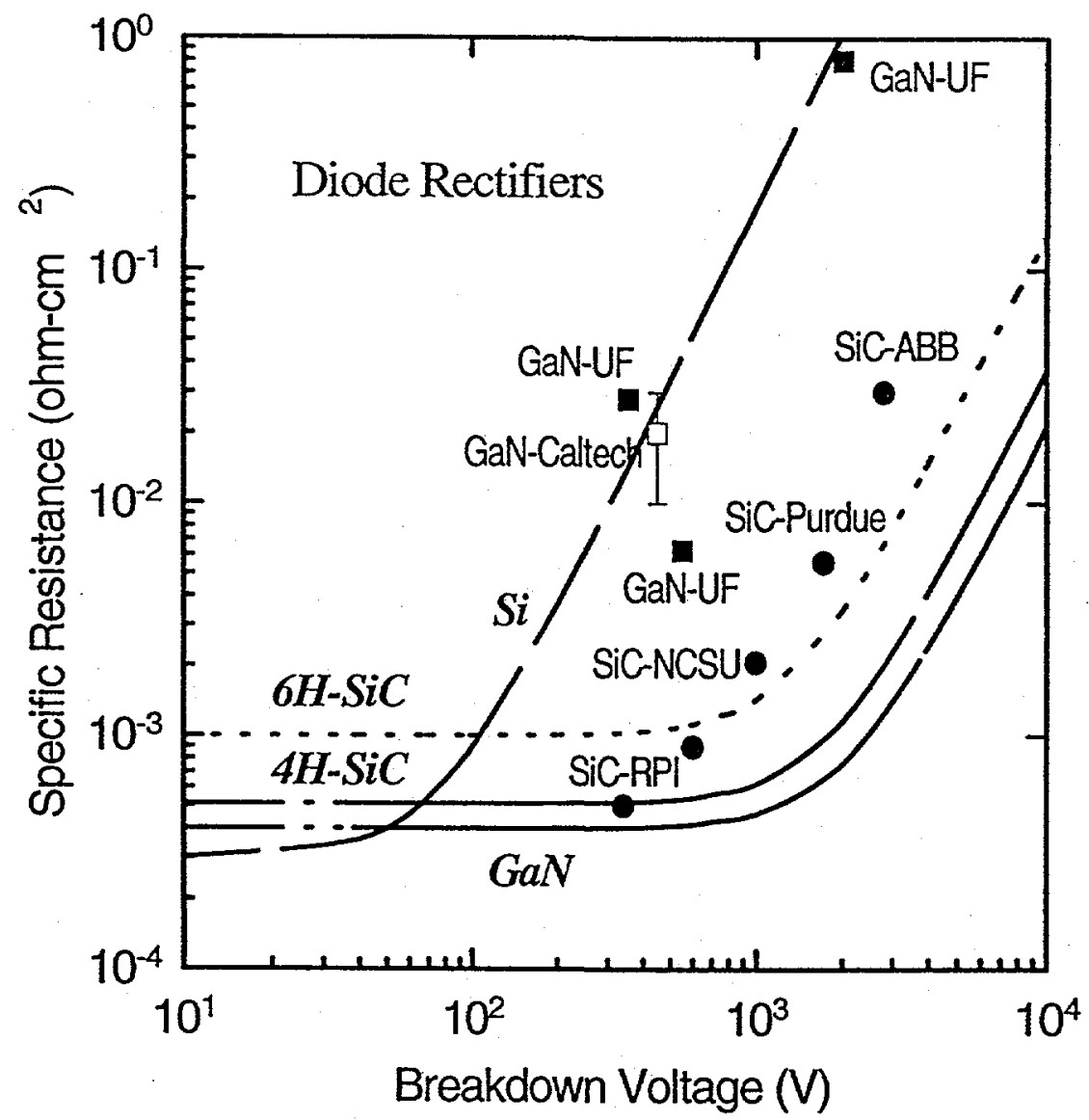

